\title{
Talking Saivism in a Tamil migrant faith classroom
}

\author{
Nirukshi Perera, Curtin University, Australia
}

Final version to appear in: International Journal of Multilingualism, 2020

https://doi.org/10.1080/14790718.2020.1712406

\begin{abstract}
This study is located in a lesser-known educational context and investigates aspects of migration, religion and multilingualism. Focusing on the discourse of second-generation adolescent migrants in a Tamil Hindu temple school in urban Australia, I discuss how flexible language practices manifest in this migrant faith setting. I argue that the use of the heritage language is not always at the forefront, despite a monolingual Tamil language policy, because religious transmission is given priority over language transmission. At the same time, there are certain motivations that influence the use of Tamil: to index the close relationship between language and religious culture and to index one's membership of the ethnoreligious community. This paper draws on ethnographic data to provide both a macro and micro view of these motivations - what drives adolescents to use their heritage language, how it is deployed from their linguistic repertoires, and how it contrasts with the use of the students' dominant language, English. The analysis takes a whole of conversation approach to understanding the relationship between religion and heritage language use for second-generation migrant students.
\end{abstract}

Keywords: religion, Tamil, Hindu temple, translanguaging, secondgeneration migrant, Sri Lanka 


\section{Introduction}

Religion is a significant social process affecting language use yet it is considerably under-recognised as an area for sociolinguistic inquiry. An overview of research regarding language and religion found a plethora of work on religious languages ${ }^{1}$ and sacred text translation, however research on 'the way that religion and language interact to produce language contact is virtually virgin territory' (Spolsky, 2003, p. 81). Omoniyi and Fishman (2006), attempted to address this with the conception of the sociology of language and religion (SLR) as a sub-disciplinary field, a marriage of the sociology of language and the sociology of religion. As an SLR inquiry, this paper contributes to knowledge about language use in migrant faith settings - to look at the site of language contact as a result of migration and subsequent sociocultural change. Specifically I will analyse the multilingual discourse of adolescent migrants in a Sri Lankan Tamil Hindu (Saiva/Saivite) temple school in Australia.

Research in migrant settings in SLR has found that the language of faith is seen as important in terms of reciting sacred texts, a key initiation rite in many communities and a 'powerful shared statement of linguistic and cultural belonging' (Gregory, Choudhury, Ilankuberan, Kwapong, \& Woodham, 2013, p. 44; see also Rosowsky, 2013). While the language in some such texts is considered purely sacred without a profane function, there are also religions which incorporate the use of everyday heritage languages such that these languages take on a sacral symbolism.

When it comes to the language policy of migrant religious institutions, leaders

\footnotetext{
${ }^{1}$ The term 'religious language' can be a language that 'is consistently used with religion' or within a religious domain of language use (Samarin. 1987, as cited in Darquennes and Vandenbussche, 2011, p.6), and also as the language that allows people to participate in religious custom.
} 
are faced with weighing up this sacral symbolism of language against the practical matter of ensuring maximum comprehensibility amongst devotees with limited knowledge of that language (Liddicoat, 2012). Souza, Kwapong and Woodham (2012, p. 118) found that language policies designed by faith leaders, which enforce the use of the heritage language, can ignore the agency of teachers and students in creating 'informal, unplanned language planning' in the migrant religious classroom. Studies such as these (for example Chew, 2014; Han, 2011) refer to the flexible language practices, which incorporate the use of dominant societal languages, adopted in faith classrooms to accommodate for the students' variable linguistic competencies and practices. However, these studies generally lack microanalyses of interactional discourse to demonstrate the how and why of these language practices.

One exception is Lytra, Gregory, and Ilankuberan's (2016) investigation of a Tamil Hindu faith teacher's approach in a Tamil-medium religious classroom in London. The authors analyse how the teacher manages the children's use of English as a diversion from the medium of Tamil. They conclude that the 'faith teacher's pedagogic approach emerged as a pragmatic and contextual response to the students' diverse capabilities in class, with the purpose of making faith literacy learning accessible and relevant to their lives' (p.554). This paper aims to build on the work of Souza et al. (2012) and Lytra et al. (2016) by providing a comprehensive analysis of some interactional practices in a Saiva faith classroom in Australia to find, not only how the teacher, but how the students negotiate language in religious discussions (see also Perera, 2018).

While only a small body of research exists on language use in migrant religious educational settings, it is important to recognise their difference to complementary language schools (for example Creese et al., 2011; Li Wei \& Wu, 
2009). Language schools hold language education as the key goal whereas heritage language-medium religious schools are often forced to prioritise religious over language maintenance given the limited time and resources to transmit aspects of culture to children in the diaspora context (for example Perera, 2016) and this can motivate some shift to English for that purpose. In this paper I argue that given that the goal of language learning is not paramount in this religious school, the use of Tamil still performs enduring roles in the religious context.

In research which treats multilingual languaging ${ }^{2}$ as code-switching, there tends to be an emphasis on what additional functions English performs as the language which deviates from the classroom medium considered to be the norm. As Bonacina and Gafaranga (2011, p. 323) point out, in such studies 'the fact of using the medium of instruction is seen as unremarkable, while the use of the other language(s) is seen as noticeable and accountable'. Avni (2012) provides an alternative model in her study of adolescent students in a Hebrew-medium non-Orthodox Jewish day school in the US. She asks not what the students do with Hebrew, the heritage language, but what it can do for them. This enables a focus 'on the semiotic and discursive practices through which individuals use (or choose not to use) a heritage language in the process of constructing and negotiating a collective sense of self' (Avni, 2012, p. 324).

This article takes a similar approach in aiming to highlight the marked ways in which the classroom medium of instruction, Tamil, is adopted by the religious

\footnotetext{
2 I use 'languaging' to mean that 'language users employ whatever linguistic features are at their disposal with the intention of achieving their communicative aims' (Jørgensen, 2008, p. 169). In this paper the term is used interchangeably with 'translanguaging'.
} 
students. I ask, what are the multiple workings of Tamil in the Saiva classroom and how does the use of other languages (mainly English) open up spaces where Tamilness is negotiated? As with Avni (2012, p. 324), the interest is in 'the enactment of ideologies' in the classroom 'as a means of understanding the relation of language and talk to broader social processes' and, in this case, religion in particular. I contend that while the second-generation migrants ${ }^{3}$ are more competent in English (or have more English features in their linguistic repertoires), it is not solely the language policy of the school that influences the use Tamil. I argue that the desire for religiocultural belonging and the strong connection between the Tamil language and Saiva religion also prompt the use of Tamil.

Therefore, this paper aims to contribute to scholarly understanding of multilingual language practices in a second-generation migrant religious education setting, through both a microanalysis of classroom interactions and an investigation into the ideologies that influence such languaging practices, especially when it comes to the use of certain Tamil features. In the next section I will provide some theory on ideologies that lead to Tamil use in the religious context and discuss the notion of flexible language practices. Following an outline of the study's context and research methodology, the findings will be presented in two parts: the macro view to look at overarching ideologies influencing students and the micro view to demonstrate how the context and ideologies manifest in classroom talk.

\footnotetext{
${ }^{3}$ Migrants who came to Australia as young children or migrants' children who are born in Australia.
} 


\section{Theoretical background}

\section{Ideologies regarding religious/heritage language use}

The ideologies that determine language use in particular religions have been conceptualised by various scholars, for example, Pandharipande (2010) refers to the 'variability' of a religion and a particular language (such that Arabic and Islam are invariable). In her research on ethnic churches in Melbourne, Woods (2004) found that, on an institutional level, the maintenance of the heritage language in worship is largely determined by the perceived strength of a language-religion ideology (LRI). A strong LRI means that a majority view the heritage language as critical for authentic religious practice. However if the connection is weak, then this allows for more dominant societal languages to seep into practices as a way to ensure the next generation's continued participation in the faith community and to potentially attract a wider population.

Research has shown that the connection between Tamil and Saivism has, historically, been strong for Sri Lankans (see Suseendirarajah, 1980, p. 347). Fernandez and Clyne's study in Australia supports this by stating 'the distinctive cultural ideology of the Hindu religion promotes the maintenance of Tamil by those who identify themselves as devout Hindus' (2007, p. 186). However, when it comes to the religious institutions, Perera's (2016) and Lytra, Gregory, and Ilankuberan's (2016) studies in Australian and UK Saivite temples report more flexible and practical approaches, allowing some use of English while still maintaining the primacy of Tamil.

These findings beg the question that, if monolingual Tamil fluency is not mandatory in migrant temples, then what specific purposes does Tamil serve for young second-generation members in this religious context? In Souza's summary of 
research in the field of SLR, she states that 'one fundamental issue in the studies of language and religion is that both aspects play an important role as identity markers' (2016, p. 207). Such studies show 'the importance of learning heritage languages in providing children with access to the religious and cultural membership of their communities' (Souza, 2016, p. 196). Other research has found that at least a display of cultural tokens or 'emblematic features' of Tamilness are needed in order to be ratified by other insiders as a legitimate community member (as in Canagarajah 2012; Creese and Blackledge 2015). Canagarajah (2019, p. 19) uses the term 'fragmented resources' to describe the way the second generation deploys Tamil features to perform certain functions such as 'styling' Sri Lankan Tamil identities; establishing in-group relationships with other Tamils; and performing resistant identities to detach themselves from the mainstream. This leads us to a discussion on flexible language practices by second-generation migrants.

\section{Flexible language practices}

Code-switching has generally been seen as "the kind of discourse in which words originating in two different language systems are used side-by-side' (Backus, 2005, p. 307). However what constitutes a language has been problematised since language is understood to be an abstraction and different languages cannot be so easily separated and categorised in practice (for example Gafaranga, 2005; Jørgensen, Karrebæk, Madsen, \& Møller, 2011). Alternative terms to language have been proposed such as ‘semiotic system' (Auer, 1995), 'feature' (Jørgensen, 2008), and 'linguistic repertoire' (Blommaert and Backus 2011). Blommaert and Backus (2011) state that individuals' linguistic repertoires represent each person's life experience as they move between different groups and sections of society. The resources in one's repertoire are indexical, and communicative competence in these resources does not rely on having 
a complete linguistic ability in a named language (Blommaert and Backus 2011).

These days the concept of code-switching has been largely superseded by the concept of translanguaging to account for the boundlessness of language. García (2009, p. 140) defines translanguaging as 'the act performed by bilinguals of accessing different linguistic features or various modes of what are described as autonomous languages, in order to maximise communicative potential'. Otheguy, García, and Reid (2015) add that if we focus on individuals' use of their full idiolect, then they are able to deploy all the lexical and structural features known to them, and for multilingual individuals, these idiolects include 'a more complex socio-cultural marking of which features to use when and where' (p.292). Tying this to the idea of ethnoreligious belonging, interactants need to understand the indexicality of heritage language features so that they can be deployed to mark Tamil identity and belonging. These concepts will be revisited in the findings section.

\section{Context and data}

Hinduism has been the fastest-growing non-Christian religion in Australia since the turn of the millennium, correlating with exponential growth in Indian immigration. However it is Sri Lankan Tamils, who immigrated between the late 1970s through to the 1990s that established some of the older Hindu temples around the country. The Saiva Temple (all site and participant names are pseudonyms) is one such temple located in an urban centre, practicing a branch of Hinduism named Saivism. Saivites view Lord Shiva as the preeminent god and Tamil Saivism, the focus of this paper, is a particular type of Saivism based on canonical Tamil Saivite texts and generating its own ethnoreligious culture. 
Between 2013 and 2016 I conducted an ethnographic study ${ }^{4}$ in the Saiva temple to gain a holistic view of the language practices occurring amongst various groups and spaces. As the ethnography progressed to a focus on the language and identification practices of second-generation devotees, I was drawn to the temple's religious school known as Greenfields Saiva School.

The Saiva Temple is the only temple offering a Tamil-medium religious school in the country. It is run by volunteers and operates out of a public school in Greenfields, an area popular with Sri Lankan Tamils. Enrolments are at approximately 50 students from Kindergarten to Year 9 (ages five to 15 years old). Most students also attend the local Saturday Tamil language school which, in comparison, had about 300 enrolments in 2015. The students at the Saiva School represent only a small proportion of young devotees at the temple, and tend to come from 'exemplary families' who are highly committed to transmitting the religion, language and culture (Warner \& Williams, 2010, p. 159).

The school runs for two hours on Sundays and staff include five Saiva teachers, two singing teachers, a few volunteer assistants and a school director. School opens at 8am with a 30-minute assembly, followed by a one-hour Saiva class (split by grades) and a 30-minute pannisai class to sing Saiva devotional songs in Tamil.

I attended the school regularly between October 2014 and September 2015 and focused mainly on the Year 9 class ${ }^{5}$ where I observed a total of 22 lessons and

\footnotetext{
${ }^{4}$ Ethics approval was granted by Monash University.

${ }^{5}$ In the Australian school system, Year 9 is the third year of high school and students are 14 to 15 years old.
} 
recorded observations in a field diary. I collected 12 hours of naturalistic video data and, with the assistance of a Tamil interpreter, transcribed and translated the interactions. I audio-recorded six hours of interviews with the Year 9 students, some of their parents, the teacher and other key players in the school. I also gave the Year 9 students a questionnaire on their backgrounds and Tamil language and cultural habits. The findings will draw from these data sources but will mainly feature interview and linguistic data.

My own positionality as an insider/outsider researcher needs mentioning at this point. As a second-generation Sri Lankan female migrant I shared some knowledge of the cultural context which helped in forming relationships, especially with the students' mothers, and I could also relate to the identification experiences of the second-generation young people. However, as a non-Tamil, (a mixed Sinhala/Sri Lankan Malay - an identification made relevant due to the ethnic tensions of the civil war) ${ }^{6}$ and a woman, there were certain challenges to maintaining trust and accessibility with some members of the temple community. My gender was pertinent to negotiations with the male-dominant temple board, some of which had brought over historically patriarchal practices from Sri Lanka. Regular attendance at the temple and learning the Tamil language helped to alleviate some of these tensions.

In analysing flexible language practices in the linguistic data I considered Auer's (1995, p. 129) proposition for Conversation Analysis (CA) to provide concrete evidence that 'politically, socially or simply personally motivated preferences for one language or the other are made visible in conversational sequences of language negotiation'. CA has been critiqued for its lack of concern with background and

\footnotetext{
${ }^{6}$ This 'burden of reconciliation' for the Sri Lankan diaspora is discussed in a forthcoming edited collection on research on Sri Lankan Tamils Australia (Kandasamy, Perera, \& Ratnam, 2020).
} 
context (Benwell \& Stokoe, 2006; Jørgensen, 2008), therefore I concur with Li Wei (2005, p. 387) that a dual-level approach is needed or in other words, a 'wholeconversation' approach (Gafaranga, 2005).to account for such 'non-linguistic' aspects, concludes, one which Interactional Sociolinguistics (IS) addresses these needs by linking the sequential analysis of code alternation (seen as the micro) to the analysis of social motivations (the macro). IS investigates the meaning negotiated in speakers' turn-taking in a communicative event, but also on 'the context and culturally specific situated inferences' that members draw on to convey their message (Gumperz, 1999, p. 458). In this paper, IS has been applied as a methodological and analytical approach to provide a comprehensive view of discourse in this religious context, and accordingly, the findings are separated into the macro and micro views.

\section{Findings}

\section{Macro view of the Year 9 Saiva class}

This first findings section outlines the factors that affect the deployment of Tamil language features from one's repertoire in the Year 9 class. To set the scene I will highlight some characteristics of the Year 9 class and outline how ideologies impacted on their views of Tamil language use.

The class comprised five regular second-generation students aged between 13 and 15 years. There were two girls: Jeya and Meena, three boys: Chitran, Raja and Thiran, and a first-generation teacher, Mrs Chandran. All the students were raised with Tamil as their first language and all attended the separate Saturday Tamil language school. 
The Year 9 teacher was flexible in her pedagogical practices in response to the migration and diaspora context. She appreciated that the children would not be able to maintain Tamil at the same level as in Sri Lanka and that English would be their necessarily dominant language. While the school had assigned a Saiva textbook written in Tamil script it was rarely followed through the whole lesson. Mrs Chandran's aim was not merely to enforce language or theological learning but to provide students with guidance about life 'through the lens of faith' (Lytra et al., 2016, p. 561). When I asked her if the Tamil language was an important component of her lessons she answered,

\section{Extract 1}

I think that my own opinion is not language, [it's] human values ... you know the Saivism is not a religion, that is life skills, you know that's discipline and life skills. (Interview 6 September 2015).

Mrs Chandran did not strictly adhere to the Tamil language policy and she sometimes explained complex concepts in English in order to facilitate the students' understanding and maintain their engagement in the classes (Lytra et al., 2016), mentioning to me after one lesson, that the students would get bored if they had to solely use Tamil in class.

While English was the dominant language for the adolescents, both inside and outside the classroom, interviews and conversations indicated their strong allegiance to the Tamil language and to its value for the religion and their sense of identity. Jeya and Meena confirmed their understanding of the connection between the religion and language. When I asked them if they thought it was important to have the classes conducted in Tamil, they agreed,

\section{Extract 2}


Jeya: But sometimes there aren't even any words in English

Meena: Like the understanding is very much based around Tamil language. it's not like, you can't explain those things in English, it doesn't make sense yeah, to explain it in English. (Interview 19 September 2015).

The implication is that students use Tamil for religious and cultural purposes due to the inadequacy of English to express relevant concepts, and I had the impression that the students were proud that a special insider code was needed to fully comprehend their religion. Similarly, a Tamil community group leader in Canagarajah's research stated that the Tamil language 'enables speakers to appreciate the nuances and subtleties of meanings related to the heritage culture' (Canagarajah, 2019, p. 18). . The unstranslatablity of culturally, and religiously, embedded concepts is highly significant to flexible language practices. Not only is the use of such 'untranslatable' heritage language features part of normal practice in many multilingual families and communities (García, 2009, p. 112), they are deployed to co-construct ethnic affiliation in interaction (Fina, 2007), especially in achieving inclusion for minority students in education settings (García \& Li Wei, 2014, p. 92).

The use of Tamil is critical to identification practices. When I asked Jeya whether being a Saivite was important to her, she answered,

\section{Extract 3}

Tamil is the language of Hinduism so um their values belong ... they share the same values so ... when I say I'm Tamil I'm Hindu as well. (Interview 19 Sep 2015). 
Jeya's answer indicates the influence of the strong LRI that links Tamil and Saivism in Sri Lanka. Tamil is seen as the inextricable language of her heritage religion and thus Tamil features are part of her symbolic repertoire in marking this ethnoreligious identity.

Closely connected to utilising Tamil language resources for identification is the sense of belonging that Tamil language competency can afford the students in the local ethnoreligious community. When I asked the boys what the Tamil language does for them Thiran said,

\section{Extract 4}

When you know your mother tongue it makes you part of the community and gives you sense of identity with other Tamils. (Interview 6 Sep 2015).

In this case, Tamil is seen as a marker of authenticity, as Avni (2012, p. 331) states, not just a matter of linguistic proficiency but of cultural proficiency, and a demarcator of group membership. Jeya also provides a perspective on ethnoreligious belonging, saying that acceptance is contingent on knowing the language,

\section{Extract 5}

It's expected of you like. (Interview 19 Sep 2015)

Whereas Thiran expresses knowing the language as a plus to his Tamilness, Jeya's words imply a level of pressure to maintain it. This is highlighted by Meena's comment that knowing Tamil was not just an expectation but a way to avoid criticism in the community, especially when faced with recent arrivals from Sri Lanka who were more competent in Tamil than her. When I suggested that receptive competency might be sufficient she corrected me,

\section{Extract 6}


Meena: $\quad .$. but also I find that um in our Tamil community if you only understand Tamil and don't speak it (they are all) kind of a bit judgmental about it

Niru: really?

Meena: or they think you're trying to be a bit Westernised. (Interview 12 Oct 2015).

These comments suggest that Meena was influenced by community and peer judgements about who was authentic and who was too assimilated.

This interview data evidences how the ideologies connecting religion and language and language and belonging enter into students' individual decisions about how they deploy their repertoires. In the diaspora context this can be especially relevant as students want to maintain the strength of Sri Lankan Tamil affiliation, language and culture in the knowledge that these core aspects of ethnicity have been under threat in Sri Lanka, during and after the 26-year long civil war (see Perera, in print). Tamil is maintained as the authentic code for expressing many Saiva religious and cultural concepts that cannot be translated accurately into English. Furthermore, the use of Tamil for such concepts marks the speaker's awareness of the cultural significance of such terms and their belonging to the speech community. The strong LRI from Sri Lanka is evident in such practices but not the sole reason for the use of Tamil. The need for Tamil competency in order to be ratified as an in-group member also gives rise to the use of Tamil features for indexing identity. In this section I have outlined some of what Tamil does for the second-generation migrants, and in the next section I will also highlight some of the functions of English in this classroom context. 


\title{
Micro view of discourse in the Saiva classroom
}

In this section I shift the lens to the micro view to determine what is actually occurring in the classroom talk and how the macro ideologies described above come into play. I will firstly provide some short examples of flexible language practices before moving to a longer extract which demonstrates how ideologies and language use intersect in this religious classroom context.

\section{Saiva funeral rites}

The following linguistic data comes from a particular lesson (on 14 June 2015) where the teacher and students were discussing Saiva funeral rites. The transcripts are presented in English and transliterated Tamil, and speech is divided into one intonation unit (IU) per line. Features categorised as Tamil are in bold and, where needed, an English translation is in italics. See appendix for transliteration and transcription details.

In the first extract, Mrs Chandran shows the students some cuttings of arugam (also known as Bermuda) grass and asks about its religious significance. Chitran's answer exemplifies flexible languaging in this religious context.

\section{Extract 7}

\author{
1 Chitran: that's piLLaiyaar's favourite pul \\ that's Ganesh's favourite grass
}

Chitran says the grass is a favourite food of Ganesh's, the elephant-headed god. He deploys the Tamil name for the deity, however, instead of affixing the Tamil suffix, uTaiya, to denote possession, he adopts the English, 's. He also uses the Tamil equivalent for 'grass', an item that has a holy aspect since it is used in various rituals. While the sentence has an English syntactic structure, the religious concepts are 
expressed in Tamil and are indications of abiding by the Tamil-Saiva LRI. In the next example, when discussing the Hindu ritual of cremation, Jeya wants to know what Muslims do with their dead.

\section{Extract 8}

1 Jeya: do they erikkiRa as well do they it burn/cremate as well? or do- puthaippaangkaLaa? or do- do they bury?

A similar pattern to Extract 7 is evident in Line (L) 1 where the question has an English frame and Jeya adopts the Tamil word for cremate (using the third person neutral (it) present form of the verb), an act with strong religious significance. In L2, however, the frame of the question changes from English to Tamil. Jeya begins her question with or do, followed by an abrupt truncation before she forms a Tamil interrogative which translates as 'do they bury' (using the third person plural present form of the word with the question suffix $-a a$ ). In L2 it appears that she is repairing the conjugation error she made in L1.The verb for 'bury' embeds the appropriate pronoun and interrogative forms in Tamil. Curiously, burial is not so relevant to Hinduism but Jeya adopts the Tamil verb perhaps to contrast it to cremation. This example suggests then that while the LRI can account for the use of Tamil there are various factors at play in flexible languaging and therefore patterns of language use are not fixed and predictable. As this case illustrates, factors like language competency and maintaining discourse flow are also at work. 
In the next extract, Meena asks a question about the use of turmeric as part of a Saiva funeral rite. She is unsure whether a paste made with turmeric is worn by the mourners or placed on the deceased.

\section{Extract 9}

1 Meena: do they put the manjchaL on the dead person's eyes or= do they put the turmeric on the dead person's eyes or?

2 Chitran: =on the dead person.

In L1, Meena's clarification question is framed in English but when it comes to 'turmeric' she deploys the Tamil feature. In this case, turmeric, the spice, has religious significance but also a secular cultural function in cooking for Tamils. Tamil names for food, including spices, are generally learnt at home, from a young age. The use of Tamil labels signify insider knowledge of the religious, social and cultural value of such items.

These short examples show how the students can adopt Tamil features for particular purposes - to index the strong LRI and the social and cultural value of certain concepts. Tamil-relevant features are deployed to mark ethnoreligious belonging. Having said that, there is evidence that such usage is not always predictable and can vary for each individual's idiolect. English features are very much part of the discourse, assisting with flow and levels of fluency. I have provided examples of how both 'languages' are at work in the students' idiolects and are mixing with each other, in integrated and intertwined ways, in terms of morphological and syntactical features, such that it is not always straightforward to delineate between English and Tamil. Next, microanalysis of a longer extract will demonstrate 
how some of these patterns typically intersect in a class discussion and can assist in performing playfulness and mockery.

\section{Ash parcel}

During the lesson on Saiva funeral rites Mrs Chandran discusses the important ritual of ash dispersion, that is, selecting the location to disperse the cremated ashes of the deceased. The transcript begins with the teacher's explanation. (See online supplementary material for accompanying sound file).

\section{Extract 10}

1 Mrs pazhaya kaalaththila en2n2a ceythaangka

Chandran: $\quad$ in the olden days what they did was

en2Taa kangka riverla koNTee= they took ((the ashes)) in the Ganges River

3 Chitran: =oh yeah=

4 Mrs =karaikkiRathu. even

Chandran: they dissolved. even

Sri Lanka ingkee ellaam.

in Sri Lanka and here, and all,

6 antha ash kuTukkiRaangka illee.

they give that ash isn't it?

they take it and keep it and

go to Varanasi 
and dissolve it in the Ganges there

10 Jeya: =no but ippa vaikkaama viTamaaTTaangkaLaam.

no but now they won't let us keep ((the ashes))

11 Mrs aa aa

Chandran: yes yes

12 Jeya: [they won't let you keep it in the house]

13 Mrs [illa athukekaNTu oru section] ethoo

Chandran: $\quad$ no for that they have reserved a particular section ((in the crematorium)) it seems*

14

vachchirukkiRaangkaL.$=$

15 Jeya: =really?

16

because when ammammaa passed away,

because when grandma passed away

we want to give it

18

like a bit of the ashes to my

19

ammaa's aNNaa in India?

mum's older brother in India

to go karaikkiRathu in the koovil or something?

to go dissolve in the temple or something

and then the immigration didn't let us

22

[we were like] like 
23 Mrs

[aa]

Chandran: yes

24 Jeya: it's foreign material or something like that=

25 Thiran: =the ghost [is going infect the pla:ne] heh

26 Mrs

[naan2 oru talkla keeTTan2aan?]

Chandran: $\quad$ I heard about it in a talk

27 Jeya: heh heh [heh]

28 Mrs [cari $]$

Chandran: okay

29 Meena: [£they] confiscated the ashes:£

30 Mrs [cari kavan2ingkoo]

Chandran: okay listen

31 Jeya: [we did get it back]=

32 Chitran: =ghost infect the plane

33 Mrs ah [can2angkaLellaam]

Chandran: ah all people

34 Thiran: [(h)oh (h)oh(h) heh]

35 Jeya: [heh heh heh]

36 Mrs listen carefully=

Chandran:

37 Jeya: ='cause after like a week we were $\mathrm{j}(\mathrm{h}) \mathrm{ust}(\mathrm{h})$

38 how 'bout grandma's ashes 
* due to SOV word order, the English translation also corresponds to the Tamil IU in L14.

In L1 and L2, Mrs Chandran tells the students how, in the past, families would travel from Sri Lanka to Varanasi in India to disperse the cremated ashes in the Ganges River. In L4 to L9, she states that even nowadays, with a widespread diaspora, families keep the ashes until they can make a trip to India to do the same. In her predominantly Tamil utterance she employs English features for emphasis, with the use of even, integrated riverla, and ash (the latter two features have Tamil equivalents that are part of the students' repertoires). In L10 Jeya begins her IU with an English negative and conjunction to disagree with the teacher before adopting Tamil features to express that 'they won't let us keep the ashes', following the teacher's pattern of speaking in Tamil. She refers to the belief that the ashes should be scattered as soon as possible after cremation to assist the deceased's prompt transition to the afterlife. Keeping the ashes for a prolonged period can attract negativity into the home. Jeya's repetition of this statement in English (L12) is known as the doubling principle (Hinnenkamp, 2003, p. 34) and could be her way of emphasising her point in English, as the teacher has done in the previous lines.

In L15 to L22, Jeya begins a narrative, relaying a personal experience concerning her deceased grandmother's ashes. The predominantly English turn contains Tamil for concepts related to kinship: 'grandma', 'mum' and 'older brother'. During the ethnography I observed the students consistently use Tamil for kinship, both as referent and address terms. This highlights the indexical value of Tamil features but also the untranslatability of Tamil kinship terms where the attributes of 
maternal or paternal, older or younger are significant to the Tamil social and cultural context and are therefore embedded into the terms. The influence of the LRI is evident in the use of Tamil for two highly sacred terms, 'dissolve' and 'temple'. In the case of koovil. 'temple', usage in the students' repertoires resembled that of a proper noun rather than an object. English features appear to bring a less-serious tone to the story, with the use of the hedges like and a bit of in L18. Also in L20, the use of or something diminishes the solemnity of the act of dissolving the ashes. After Jeya reveals that the immigration did not allow her family to take the ashes to India, Thiran reacts with a joke in L25. This is directed at the two boys sitting next to him and delivered with an eerie tone, the ghost is going [to] infect the plane, followed by laughter.

From L24 the amount of latching and overlapping talk increases as the students become more enlivened, and this faster-paced talk spurs on the use of English for discourse flow. Mrs Chandran tries to change the footing in L26 (to refer to her utterance in L13 and L14) but there is no uptake. In L27 Jeya laughs in reaction to Thiran's joke and in L29 Meena directs a clarification question to Jeya in English, more so to signal her amusement than seek confirmation. The teacher makes two attempts (L30 and L33), in Tamil, to control the class however the students do not seem to hear her. She shifts to English in L36 as a last-resort effort to regain control. Here the teacher accommodates to the students' extended interaction in English, as a way of entering into the discussion and taking the floor. However it does not work in this case.

L32, L34 and L35 see more joking and laughter from the students. While the idea of a ghost on a plane is nonsensical it does have some basis in the belief that keeping the ashes for too long attracts negativity (see also Grønseth, 2018). The 
joke's intention could also be to mock the apparently ignorant thinking of the authorities that stopped the sacred ashes from going overseas. In L37 to L39, Jeya continues the story in English but deploys the Tamil karaikkiRathu as the apt verb for the ritual of dissolving the ashes in the river. This is a highly sacred practice for Hindus and for Tamil Saivism, such a religio-cultural concept does not translate easily into English. Jeya laughs at the absurdity of her grandmother's body (in essence) leaving for India but then returning home, waiting to be dealt with. If the ashes were kept in the house this could reopen the possibility for misfortune to come their way. In Extract 10, there is a curious interplay of LRI adherence and in-group membership for the purposes of light-hearted mockery even though it concerns a religio-cultural problem with sombre implications for Jeya's family. The secondgeneration migrants tread the fine line between showing respect for Saiva rituals and their culture while being playful at the same time - partly achieved through the use of English features, but only adequately executed through the use of both Tamil and English. It is in this type of languaging that the mockery more effectively achieves its goal and has a unifying effect on the teenagers (see Jørgensen, 2008).

Thiran's joke about the ghost draws from both inside and outside the boundaries of the religion to incite humour. As insiders, the Saiva students have an appreciation of the irony in trying to adapt certain rituals such as cremation to a transnational diaspora context, one where the religion must contend with secular authorities in Western settings. By making this joke in English, Thiran creates symbolic distance from the serious tone of the Saiva ritual, and perhaps also, manages to get away with it without the teacher noticing. If he was an outsider to the group, such a joke would have been seen as poor taste, however it creates delight for the teenagers. Thus, the students' use of English for mockery, and Tamil for LRI and 
marking Tamil identity, displays their understanding of the indexicality of both languages. In this sense, translanguaging has been adopted to facilitate the expression of 'new social realities' that have arisen from migration and adapting a religion to 'a new way of being in a different social, cultural or political context' (García \& Leiva, 2014, p. 204).

\section{Conclusion}

This paper has explored the flexible language practices in a migrant faith classroom context, and by doing so, has contributed to an understanding of how religion and language intersect for second-generation migrants. By taking a 'whole-conversation approach' (Gafaranga, 2005) both the macro and micro perspectives have been considered. A microanalysis of naturalistic linguistic data has highlighted how sacral symbolism (via the strong LRI) has an enduring influence on the use of the related heritage language in migrant religions. At the same time there is evidence of a weakening of the LRI that allows for flexible languaging to occur.

The interview extracts evidenced the students' desire to be affiliated with the Tamil Saivite community and for this to be linked to their identity. They may not be able to abide by a monolingual Tamil-medium language policy in the faith classroom due to variant levels of competency, but they understand the significance and markedness of deploying Tamil features not only for religious, but for socio-cultural, practices. Furthermore, there are cases where a Tamil concept is culturally and religiously nuanced and cannot be easily translated into English. Overall, the linguistic extracts present how religious and cultural practices provide contexts to help young people deploy these Tamil resources from their repertoires (see also Canagarajah, 2019). 
Revisiting Avni (2012), the findings support the notion that it is not only about what the students do with the Tamil language, but what the Tamil language does for them. I propose that the use of the heritage language is more relevant in the diaspora, than in the homeland, for indexing ethnoreligious belonging by younger generations. While the use of Tamil can be taken for granted in young Tamil communities of practice in Sri Lanka, the same cannot be assumed for the Australian context where English features tend to dominate young second-generation migrants' repertoires. Deploying Tamil features in their speech, especially for social, cultural and religious functions, is critical identification work for claiming membership of the Sri Lankan Tamil diaspora.

I have also shown how the use of English assists with negotiating Tamilness. English features help to maintain the flow of discourse which incorporates Tamil features, and they can fill in the gaps where competence in Tamil is lacking. English has also been deployed for jocular purposes, but it is only when combined with Tamil features, which signal in-group membership, that the multiple layers of meaning and humour can be conveyed. While I cannot argue that all uses of 'Tamil' and 'English' are conscious and strategic, I suggest that the interlocutors strongly associate some feature choices with indexical, socio-cultural markings.

This study shows that despite the children's strong competency in English, they have grown up with the Tamil language and want to continue to hold on to their sense of Tamilness. As part of this motivation, they appreciate the strong place of Tamil in the practice and culture of Saivism.

\section{Appendix}

\section{Details about transliteration}


Tamil does not have a standardised transliteration scheme for Romanisation so there are a variety of approaches by scholars. I use a system based on the work of grammarian Harold Schiffman (1999) from the University of Pennsylvania. In this system long forms of vowels are represented as a sequence of two same vowels (e.g. Y is $a$ and $\%$ is $a a$ ) and similar sounds are differentiated without diacritics (e.g. the alveolar nasals: ந் is $n$ and ன் is $n 2$, and the velar nasal: ண் is $N$ ). See Perera (2017) for further details.

\section{Transcription symbols}

[ ] overlapping talk

(( )) author's description

- $\quad$ cut-off or self-interruption

$=\quad$ latching

: $\quad$ prolonged sound

word stress or emphasis

continuing intonation

final intonation

? rising intonation

heh laughing word

(h) Breathing or laughing within a word

$£ \quad$ smile quality 
Funding details: The writing of this article was supported by a Postgraduate Publications Award from Monash University.

Disclosure statement: No potential conflict of interest was reported by the author.

Acknowledgements: My gratitude goes to the members of the Year 9 class and to the Director of Education at the Saiva Temple for their cooperation. I thank Dr Louisa Willoughby at Monash University for her valuable advice and the anonymous reviewer for such helpful feedback on improving this article. I wish to acknowledge the late Tope Omoniyi for inspiring research on language and religion.

Biographical note: Nirukshi Perera was awarded a PhD in 2017 for her thesis on language practices in a Tamil Hindu temple. In 2018 she was the winner of the Australian Linguistic Society/Applied Linguistics Association of Australia Michael Clyne prize for Best Thesis on Immigrant Bilingualism and Language Contact and the joint winner of the Australian PhD Prize for Innovations in Linguistics. She is interested in the connections between language, culture, religion and identity for Sri Lankan migrants, particularly for second-generation youth, investigated via ethnography and discourse analysis.

Supplemental online material: Extract10.AshParcel.m4a (audio file) 


\section{References}

Auer, P. (1995). The pragmatics of code-switching: A sequential approach. In L.

Milroy \& P. Muysken (Eds.), One Speaker, Two Languages: Cross-

Disciplinary Perspectives on Code-Switching (pp. 115-135). Cambridge, UK:

Cambridge University Press.

Avni, S. (2012). Hebrew as heritage: The work of language in religious and communal continuity. Linguistics and Education, 23(3), 323-333. https://doi.org/10.1016/j.linged.2012.06.004

Backus, A. (2005). Codeswitching and language change: One thing leads to another? International Journal of Bilingualism, 9(3-4), 307-340.

Benwell, B., \& Stokoe, E. (2006). Discourse and identity. Edinburgh: Edinburgh University Press.

Blommaert, J., \& Backus, A. (2011). Repertoires revisited: "Knowing language” in superdiversity. Working Papers in Urban Language and Literacies, 67, 1-26.

Bonacina, F., \& Gafaranga, J. (2011). 'Medium of instruction' vs. 'Medium of classroom interaction': Language choice in a French complementary school classroom in Scotland. International Journal of Bilingual Education and Bilingualism, 14(3), 319-334. https://doi.org/10.1080/13670050.2010.502222

Canagarajah, S. (2012). Styling one's own in the Sri Lankan Tamil diaspora: Implications for language and ethnicity. Journal of Language, Identity, and Education, 11(2), 124-135. https://doi.org/10.1080/15348458.2012.667309

Canagarajah, S. (2019). Changing orientations to heritage language: The practicebased ideology of Sri Lankan Tamil diaspora families. International Journal of the Sociology of Language, (255), 9-44. 
Chew, P. G.-L. (2014). Language choice and religious identities in three Singaporean madrasahs. International Journal of the Sociology of Language, 2014(229), 49-65. https://doi.org/10.1515/ijsl-2014-0017

Creese, A., \& Blackledge, A. (2015). Translanguaging and identity in educational settings. Annual Review of Applied Linguistics, 35, 20-35. https://doi.org/10.1017/S0267190514000233

Creese, A., Blackledge, A., Baraç, T., Bhatt, A., Hamid, S., Li, W., ... Yağcioğlu, D. (2011). Separate and flexible bilingualism in complementary schools: Multiple language practices in interrelationship. Journal of Pragmatics: An Interdisciplinary Journal of Language Studies, 43(5), 1196-1208. https://doi.org/10.1016/j.pragma.2010.10.006

Darquennes, J., \& Vandenbussche, W. (2011). Language and religion as a sociolinguistic field of study: Some introductory notes. Sociolinguistica, 25, $1-11$.

Fernandez, S., \& Clyne, M. (2007). Tamil in Melbourne. Journal of Multilingual and Multicultural Development, 28(3), 169-187. https://doi.org/10.2167/jmmd488.0

Fina, A. D. (2007). Code-switching and the construction of ethnic identity in a community of practice. Language in Society, 36(3), 371-392. Retrieved from JSTOR.

Gafaranga, J. (2005). Demythologising language alternation studies: Conversational structure vs. social structure in bilingual interaction. Journal of Pragmatics: An Interdisciplinary Journal of Language Studies, 37(3), 281-300. https://doi.org/10.1016/j.pragma.2004.10.002 
García, O. (2009). Education, multilingualism and translanguaging in the 21st century. In A. Mohanty, M. Panda, R. Phillipson, \& T. Skutnabb-Kangas (Eds.), Multilingual Education for Social Justice: Globalising the Local (pp. 128-145). New Delhi: Orient Blackswan (former Orient Longman).

García, O. \& Leiva, C. (2014). Theorizing and enacting translanguaging for social justice. In A. Blackledge \& A. Creese (Eds.), Heteroglossia as Practice and Pedagogy (pp. 199-216). https://doi.org/10.1007/978-94-007-7856-6_11

García, O. \& Li Wei. (2014). Translanguaging: Language, bilingualism and education. Basingstoke: Palgrave Macmillan.

Gregory, E., Choudhury, H., Ilankuberan, A., Kwapong, A., \& Woodham, M. (2013). Practice, performance and perfection: Learning sacred texts in four faith communities in London. International Journal of the Sociology of Language, 2013(220), 27-48. https://doi.org/10.1515/ijsl-2013-0012

Grønseth, A. S. (2018). Migrating rituals: Negotiations of belonging and otherness among Tamils in Norway. Journal of Ethnic and Migration Studies, 44(16), 2617-2633. https://doi.org/10.1080/1369183X.2017.1389026

Gumperz, J. J. (1999). On interactional sociolinguistic method. In S. Sarangi \& C. Roberts (Eds.), Talk, work and institutional order. Discourse in medical, mediation and management settings (pp. 453-471). Berlin: Mouton de Gruyter.

Han, H. (2011). Social inclusion through multilingual ideologies, policies and practices: A case study of a minority church. International Journal of Bilingual Education and Bilingualism, 14(4), 383-398. https://doi.org/10.1080/13670050.2011.573063 
Hinnenkamp, V. (2003). Mixed language varieties of migrant adolescents and the discourse of hybridity. Journal of Multilingual and Multicultural Development, 24(1-2), 12-41. https://doi.org/10.1080/01434630308666487

Jørgensen, J. N. (2008). Polylingual languaging around and among children and adolescents. International Journal of Multilingualism, 5(3), 161-176. https://doi.org/10.1080/14790710802387562

Jørgensen, J. N., Karrebæk, M., Madsen, L. M., \& Møller, J. S. (2011). Polylanguaging in superdiversity. Diversities, 13(2), 23-37.

Kandasamy, N., Perera, N., \& Ratnam, C. (Eds.). (2020). A sense of viidu: The (Re)creation of 'Home' by the Sri Lankan Tamil Diaspora in Australia. Singapore: Palgrave Macmillan.

Li Wei. (2005). “How can you tell?”: Towards a common sense explanation of conversational code-switching. Journal of Pragmatics: An Interdisciplinary Journal of Language Studies, 37(3), 375-389. https://doi.org/10.1016/j.pragma.2004.10.008

Li Wei, \& Wu, C.-J. (2009). Polite Chinese children revisited: Creativity and the use of codeswitching in the Chinese complementary school classroom. International Journal of Bilingual Education and Bilingualism, 12(2), 193211. https://doi.org/10.1080/13670050802153210

Liddicoat, A. J. (2012). Language planning as an element of religious practice. Current Issues in Language Planning, 13(2), 121-144. https://doi.org/10.1080/14664208.2012.686437

Lytra, V., Gregory, E., \& Ilankuberan, A. (2016). Bridging faith, languages and learning in London: A faith teacher reflects upon pedagogy in religious 
instruction classes. Language and Education, 30(6), 554-569.

https://doi.org/10.1080/09500782.2016.1221419

Omoniyi, T., \& Fishman, J. A. (2006). Explorations in the Sociology of Language and Religion. Amsterdam ; Philadelphia: JBenjamins.

Otheguy, R., García, O., \& Reid, W. (2015). Clarifying translanguaging and deconstructing named languages: A perspective from linguistics. Applied Linguistics Review, 6(3), 281-307. https://doi.org/10.1515/applirev-2015-0014

Pandharipande, R. V. (2010). Authenticating a tradition in transition: Language of Hinduism in the US. In T. Omoniyi (Ed.), The Sociology of Language and Religion. Change, Conflict and Accommodation (pp. 58-83). Basingstoke: Palgrave Macmillan.

Perera, N. (2020). Tamil Weekends: Intergenerational Perspectives on Belonging. In N. Kandasamy, N. Perera, \& C. Ratnam (Eds.), A sense of viidu: The (Re)creation of 'Home’ by the Sri Lankan Tamil Diaspora in Australia. Singapore: Palgrave Macmillan.

Perera, N. (2016). Tamil in the temples: Language and religious maintenance beyond the first generation. Multilingua: Journal of Cross-Cultural and Interlanguage Communication, 35(5), 535-559. https://doi.org/10.1515/multi-2015-0059

Perera, N. (2017). Talking Tamil, Talking Saivism: Language practices in a Tamil Hindu temple in Australia (Doctoral dissertation, Monash University). https://doi.org/10.4225/03/58ffdf87350a0

Perera, N. (2018). Gesture and translanguaging at the Tamil temple. In E. Adami \& A. Sherris (Eds.), Making signs, translanguaging ethnographies: Exploring urban, rural and educational spaces (pp. 112-132). Clevedon: Multilingual Matters. 
Rosowsky, A. (2013). Faith, phonics and identity: Reading in faith complementary schools. Literacy, 47(2), 67-78. https://doi.org/10.1111/j.17414369.2012.00669.x

Schiffman, H. F. (1999). A reference grammar of Spoken Tamil. Cambridge: Cambridge University Press.

Souza, A. (2016). Language and religious identities. In S. Preece (Ed.), The Routledge Handbook of Language and Identity (pp. 195-209). Milton Park, Abingdon, Oxon; New York, NY: Routledge.

Souza, A., Kwapong, A., \& Woodham, M. (2012). Pentecostal and Catholic migrant churches in London - The role of ideologies in the language planning of faith lessons. Current Issues in Language Planning, 13(2), 105-120. https://doi.org/10.1080/14664208.2012.678977

Spolsky, B. (2003). Religion as a site of language contact. Annual Review of Applied Linguistics, 23, 81-94. https://doi.org/10.1017/S0267190503000205

Suseendirarajah, S. (1980). Religion and language in Jaffna society. Anthropological Linguistics, 22, 345-62.

Warner, R. S., \& Williams, R. H. (2010). The role of families and religious institutions in transmitting faith among Christians, Muslims, and Hindus in the USA. In S. Collins-Mayo \& P. Dandelion (Eds.), Religion and Youth (pp. 159-165). Farnham: Ashgate Publishing Ltd.

Woods, A. (2004). Medium or Message?: Language and Faith in Ethnic Churches. Clevedon: Multilingual Matters. 